Portland State University

PDXScholar

$1-1-2011$

\title{
Marginalized Characters in Contemporary American Short Fiction
}

Timur Shishkin

Portland State University

Follow this and additional works at: https://pdxscholar.library.pdx.edu/open_access_etds Let us know how access to this document benefits you.

\section{Recommended Citation}

Shishkin, Timur, "Marginalized Characters in Contemporary American Short Fiction" (2011). Dissertations and Theses. Paper 297.

https://doi.org/10.15760/etd.297

This Thesis is brought to you for free and open access. It has been accepted for inclusion in Dissertations and Theses by an authorized administrator of PDXScholar. Please contact us if we can make this document more accessible: pdxscholar@pdx.edu. 


\title{
Marginalized Characters in Contemporary American Short Fiction
}

by

\section{Timur Shishkin}

A thesis submitted in partial fulfillment of the requirements for the degree of

\author{
Master of Arts \\ in \\ English
}

Thesis Committee:

Peter Carafiol, Chair

Jennifer Ruth

Hildy Miller

Portland State University

(C)2011 


\begin{abstract}
The focus of the present research work is the contemporary American short stories that bring up issues of compulsory norm and the conflict between marginalized characters and their environment. This research was based on those short stories that seemed to represent the idea of being "different" in the most complex and multilayered way, and its goal was to unfold new aspects of the conflict between "normal" and “abnormal"/"different". Variations of norm as well as diversity within the marginalized raise a number of questions about the reasons for their inability to coexist peacefully. The close reading and the analysis of the selected stories show that all the conflicts in them, in one way or another, repeat similar patterns and lead to the same root of the problem of misunderstanding, which is fear. To be more precise, all the cases of hate towards "different" characters can be explained by the hater's explicit or implicit fear of death in its various forms: inability to procreate one's own kind, cultural or personal self-identity loss, actual life threat in the form of a reminder of possible physical harm and death. Most often it would be the case where shame and fear of death overlap in a very complex way. In general, the cases of characters' otherness fall into three major groups. The nature of the alienation for each of these groups is described and analyzed in three separate chapters. Prejudice and stereotypes are playing a great role in formation of fears and insecurities which need to be dismantled in order to make peaceful coexistence possible. This work concludes with pointing out the crucial role of taking an approach of representation of various perspectives and diversification of voices in creative writing, academia and media in the context of multicultural society.
\end{abstract}




\section{Dedication}

I dedicate this work to my beloved mother Irina Dmitriyevna Shishkina, and dearest Pyotr Nikolaevich Vlasov (Dyadya Petya) and his wife Valentina Vlasova (Tyotya Valya) who I consider my grandparents. I can't possibly express with words how important these three people are for me and how much I love them. 
Acknowledgements

Of the many people who have been providing exceptional help to me in preparation of this thesis, I am especially thankful to my Academic and thesis Advisor Professor Peter Carafiol, whose wise guidance, understanding and patient supervision allowed me to earn this degree. A very special recognition needs to be given to my professors Dr. Hildy Miller and Dr. Jennifer Ruth, whose classes helped me to approach American literature and criticism from a new perspective. I am very glad that all these three professors kindly agreed to be the committee members for my graduation.

This research could not have been possible without a fantastic opportunity to study in the United States which was generously granted to me by the Fulbright Program. I would like to acknowledge and extend my heartfelt gratitude to Cindi Barrett, James and Jane Hutcheson, Natalia Smirnova, Tom Koerber and Sarah Boeving who helped my participation in this program happen, for their encouragement and support.

I am very grateful to my friends Sandra Derrick, Michelle Cabrera, Erik Wegner, David Sanders, Kyle DeOnier, Stephanie Austin, Anna Anatolievna Yatsenko, Charles Bonds, and Avidan Schecter for the time they have spent to read this thesis and share their understanding of it. Their care about the topic and faith in me were the greatest help. 
Table of contents

Abstract $\quad$ i

Dedication $\quad$ ii

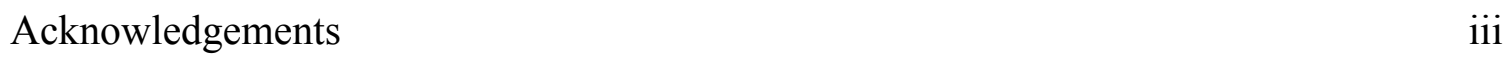

Introduction $\quad 1$

Chapter 1 The Conflict Between Normal and Different 5

$\begin{array}{ll}\text { Chapter } 2 \text { Misfits } & 8\end{array}$

$\begin{array}{ll}\text { Chapter } 3 \text { The Disowned } & 20\end{array}$

Chapter 4 Marginalized by Outcasts

$\begin{array}{ll}\text { Conclusion } & 50\end{array}$

$\begin{array}{ll}\text { References } & 53\end{array}$ 


\section{Introduction}

The last twenty five years of American pop-culture, film and literature seems to be more and more often focused on the issue of being different. Academy Awards nominees and winners more and more often include films about racism ("Crash", “Invictus", "Driving Miss Daisy”), nationalism ("Munich”), people with disabilities ("Rain Man", “Awakenings") and queer people ("Boys Don't Cry”, "Milk”, "Brokeback Mountain", "Transamerica"). Many of contemporary authors raise the same issues in their works.

Short stories were chosen for the analysis of the "different" characters in this work for several reasons. One of them is the nature of short story itself. The author of numerous short stories, Tobias Wolff, once said in an interview: "People are always asking me why more people don't read short stories, given the press of time we all experience now. It would seem to be the logical form for our culture. And I think the reason is exactly the reason people don't read poems. Because short stories are very demanding in their way. You have to be kind of clued into them, they are a world of their own, and most people find them disappointing because the best short stories are not constructed like novels. They don't have clear endings; they don't tell you everything; they work much more through implication" [Wolff, interview, 2]. Another reason to choose short stories was in the aim of the research to convey an analysis of the latest pieces of fiction that are focused on discrimination, alienation and inequality of the different by authors with various background, and the form of short story allowed studying more authors within limited timeframe. The best sources were The Scribner Anthology of Contemporary Short Fiction (selected from a survey of more than five 
hundred English professors, short story writers, and novelists) and The Best American Short Stories 2009. This research was based on those short stories, out of about seventy, that seemed to represent the idea of being "different" in the most complex and multilayered way.

The present research work consists of four chapters. Each chapter unfolds its own aspect of the conflict between "normal" and "abnormal"/"different".

Chapter one introduces main categories of "abnormal"/"different" characters. It also raises several questions that are important for this research. If the characters described and analyzed in the contexts of their environments are "abnormal", what constitutes that "norm" that they do not fit in? Even though, the perception of norm is quite relative, our research is based on contemporary American ground. Chapter one of the present work is focused on the subject of "normal" as an opposition to "abnormal", different, marginalized in western society. Variations of "norm" as well as diversity within marginalized and "abnormal" raise, in their turn, questions such as why do normal and abnormal conflict? What are the reasons for their inability to coexist peacefully? All the conflicts in these stories, in one way or another, repeat similar patterns and lead to the same root of the problem of misunderstanding in them, which is fear. To be more precise, all the cases of hate towards "different" characters can be explained by the hater's explicit or implicit fear of death in its various forms: inability to procreate your own kind (for instance, when an alienated child is gay or disabled), self-identity loss (culturally different neighbors), actual life threat in the form of a reminder of possible physical harm and death (in case of a character's sickness, for example). Most often it would be the case where shame and fear of death overlap in a very complex way. 
In general, the cases of characters' otherness fall into three major groups. The nature of the alienation for each of these groups is described and analyzed in three separate chapters.

Chapter two is about the characters who are strangers to those who do not accept them because they are alien/different from the majority. These characters are "from another team" (different race, different age group, different ethnicity). The cluster of characters illustrating this chapter includes three central marginalized characters in Leslie Marmon Silko's Tony's Story, a Native American youth, his cousin who does not relate to his original descend anymore and a white policeman in the reservation who harasses them both. The self-identity loss here becomes a question of life and death.

Chapter three is focused on more complicated situations where the "different" characters are disowned by their own families who want them to be "normal" and cannot peacefully co-exist with them because of the shame or disappointment. Besides two other stories, this chapter includes Greg Hrbek's Sagittarius in which different character is not quite human what does not allow putting him in a frame of any common categories or stereotypes, but at the same time it gives the author a priceless opportunity to reveal the absurdity and hypocrisy of discrimination and treating "others" differently. Father's obsession with operations on an absolutely healthy but different child is not based on care for his son, it is a shame of failure to leave "normal" posterity, to procreate, it is a fear that his life will not be continued in future generations, what boils down to the fear of death again.

Chapter four describes and analyzes the most interesting and complicated cases where one hates the different while he is different himself and they belong to the same 
minority group (same sexual orientation, same race, same social status, and same ethnicity). Reginald McKnight's The Kind of Light That Shines on Texas, for instance, where racism is addressed to people of one's own race in combination with self-hatred when the color of skin becomes a matter of survival for the main character. 


\section{The Conflict Between Normal and Different}

In order to start the analysis of the selected marginalized characters, it is important to discuss what constitutes the norm, which is used as a point of reference for consideration of these characters as abnormal, different, what makes them outcasts in the societies they live in. As Allan Gardner Lloyd Smith mentions, "without a norm, the abnormal cannot be perceived". [Lloyd Smith, ix]. Or, may be, norm cannot be established without knowing and feeling what is abnormal. Even though, the perception of norm is quite relative, because normal in one society, one group of people, one system of values, may as well be abnormal in another environment, our research is based on contemporary American ground.

References to canon are very common among rhetorical works on gender, articles by feminist authors and queer theorists; in studies by Black, Chicano, Native American researchers. The concept of norm is often implied in articles and books on immigration and disability.

Mark J. Justad writes in one of his works: "I readily admit then, that I "am" a white, middleclass-ish, heterosexual, male, and that this essay reflects biases associated with these particular aspects of who I am" [Justad, 357]. Ian Barnard claims: "This very privileging of sex, sexuality, and sexual identity as axis of analysis means also that its model subjects are assumed to be white, since, as I have suggested, in a society structured around race and racism at every level it is only white queers (and white people in general) who can have the luxury of not naming race, not naming their own race" [Barnard, 15- 
16]. In her interview, Judith Butler elaborates on women being expected to play the role of a mother, to have children: "If you are in your late twenties or your early thirties and you can't get pregnant for biological reasons, or maybe you don't want to, for social reasons - whatever it is - you are struggling with a norm that is regulating your sex" [Butler, interview, 5].

After all, the works of these and many other theorists, if summarized, lead to one and the same hypothetical and mysterious white, middle-class and middle-aged, heterosexual male with no disabilities, born and raised Christian in the United States. The conclusion is not so unpredictable. Though to narrow everything down to this hypothetical figure would mean to oversimplify the problem, or at least to show just one, the most explicit, of its facets. According to K. F. Rawson, "Canonization is an inherently normativizing process because it requires limits and standards of judgment that are oppressive to those who don't fit its norms" [Rawson, 42] but the complexity of the problem of being different, with all the factors affecting it, does not allow us to be satisfied with this primitive cause.

Variations of "norm" in different social groups, as well as diversity among the marginalized and "abnormal", invite us to shift the focus from the question of what is a norm and who traditionally would be considered abnormal. For example, in Tony's Story by Leslie Marmon Silko, an outcast is a middle-aged, white, male police officer. What becomes more relevant in the context of a wide variety of outcasts is why those who are "normal" and those who are "abnormal" conflict, and what their reasons for the inability to coexist peacefully are. 
In order to show the complexity of the problem of marginalization, the selection of the "different" characters in this research is limited to more unusual and complicated cases than situations strictly racist or homophobic for example. Such cases as a rule reveal more unexpected sides of discrimination and hatred, and as further chapters argue, their analysis inevitably leads to the same root - the fear of death, in its most various and implicit forms and representations. 


\section{Misfits}

One of the most common patterns in cases of marginalization is the discrimination of minority groups by the predominate group in the society. Such situations can be illustrated by characters who came from another country and are now discriminated on the basis of their religion which is not traditional for the given area. It may be an example of a gay person exposed to a homophobic group of straight people, or a child with a mental disability being harassed by children without it.

Joseph Saleeby, the main character of Anthony Doerr's short story The Caretaker is isolated from the rest of the world, outside his and his mother's house in Liberia. In a way, she isolated him. He is quiet and often sick, so his mother makes his bed and each of his meals. He is not allowed to leave the house until he reads a column of the English dictionary. The neighbors are curious about the strange man and they gaze over his mother's shoulder at the dark shuttered windows of the house where he is hiding from life. He is thirty-five years old but his mother watches him eating each lunch, and she makes sure that he finishes his meals at work. She controls his life and at the same time she has no idea that he writes extra checks to himself at the company where he clerks and that when he loses his job he pays boys to steal from downtown businesses and hide the goods in his backyard and cellar. Like many children of omnipotent mothers, Joseph has his secret discreet life being at the same time absolutely dependable on her in his everyday routine.

When his mother disappears after explosions at the market where she works, Joseph finds himself trapped in a new kind of solitude. He needs to have contact with 
people to find his mother but at this time the war is going on and he cannot communicate with anybody because he is either not used to it or people are just scared by what happens around them. The girl he stops at the scene of explosions is shocked and would not talk with him in this chaos, as well as his neighbors are now hiding in their houses, the way he used to do it when his mother has not been gone yet.

The paradox of the whole situation is that when the life was peaceful he had to hide from everybody and now he goes out into the war zone because he needs to find his mother. Joseph does not do it only because he cares about her and wants to help her, but also because her total control over his life was the only condition of his safety. His mother has been in charge of his life for decades, and staying by himself is actually more frightening to him than being out in the streets when he tries to find her and regain her protection.

“The next night - his mother does not return - he goes out again" [153]. When he finally leaves the house for good, the only thing he takes with him besides money is his mother's dictionary that she used to make him read before he would be allowed to leave the house. This is a symbol of her power over him as well as something that played the role of a pass to the outside world for him for many years. There seems to be no use in the dictionary for him though, because he cannot communicate with anybody, and it is not his choice to be silent. He becomes a witness of dialogues and conversations but "No one he sees will speak to him" [153], "No one speaks" [155] are repetitive descriptions of several situations that Joseph goes through. Even when he offers money to patrol to bribe them so they let him go, the soldier does not say a word to him and goes away instead. He leaves to talk on the radio and then to come back and follow the given order to arrest 
Joseph. The author manages to create situations in which it would make sense that other characters are silent, but the more this silence is pointed out the clearer it is that there is a message hidden in this pattern. In fact, Joseph does not get in trouble until people start talking with him. The first words spoken to him is the request to kill an alleged pilot, or just a cook, as the executed person claimed he was. Joseph has to do what he is told to do in order to survive. This is the first but not the only case when he speaks with somebody and it gets him in trouble.

After Joseph manages to escape from Liberia, he comes to Oregon and becomes a refugee of war. He finds a job at a farm working for the Twymans who are desperately looking for a person to take care of their property during the winter. The only thing Mr. Twyman says hiring him is "Your lucky day" [157]. Brief conversations with Mr. Twyman are the last conversations Joseph would have in the next several months, and as the reader finds out closer to the end of the story, this employment will dramatically chance Joseph's life. The next talk with Twyman will be about expelling Joseph from the property with shame.

Wherever Joseph happens to be he does not belong to his environment. It changes from one extreme to another, from being surrounded by terrorists in his country to millionaires "from something to do with computers". In his home country he sees mutilated corpses after fights and bombings, here in the States, he scrubs salmon off the walls after food fights among rich people.

"For two months he speaks to no one, sees no one" [158], until a group of whales strands on the beach a half mile from the estate which Joseph is taking care of. He sees how people turn this disaster into a spectacle. They cut dead whales right next to the one 
which is still alive. The stranded whales bring back terrible memories from Joseph's past. Looking into a whale's brown bloodshot eye for him is "as if some portal from his nightmares has opened" [159]. Back at home he saw terrible things that humans did to each other, disrespecting life and corrupting the natural order of it. Here he sees how humans disrespect life in a different way, by mistreating the nature, abusing its resources. The scientists do research to help other whales in future but they cut other whales right in front of the only one of them that is still alive what horrifies Joseph as he thinks about it. The woman who points out that even if the whales are towed off the beach they would probably turn and swim back onto the shore makes Joseph think that the lesson he should be learning from this is that "he is beyond saving" [159], as if "the only kind of man who can be saved is the man who never needed saving in the first place" [159].

The text is rich with symbols of death and imagery that reminds of Joseph's home associated with fears and pain. One of the most vivid of these images is a dead whale's heart with its ambivalent meaning of something once alive and warm, representing the soul and struggle with death, and at the same time now dead and unburied. Joseph extracts the dead whales' hearts and buries them in the woods. Doing that he tries to find a way out of being forced to witness the endless pattern of injustice and senseless deaths, of violation of the right order of life. "At least I have buried something", he says [162]. It is very important for him to get something buried, because there is no grave for his mother who he had never found after bombing, there was no grave for a man he had been ordered to kill back in Liberia. "Somewhere, he thinks, there is a piece of ground waiting for me" [163]. 
So, what is Joseph afraid of - death, or reality of life which scares him with responsibilities? "Because Joseph does not switch on the de-icing cables, the weight of ice collapses a section of the roof" [162]. There was a very similar situation in his home town, where his mother would wonder why he did not realize the necessity of sweeping the dust around their house which the winds from the desert brought every day. Mrs. Twyman is very angry with him and she keeps telling him about the issue of duty and responsibility. But he does work hard, not for people though, but for the right order when he digs deep graves for the whales' hearts. He works hard taking care of new plants that he grows in the woods. He does have a sense of duty and responsibility, only for nature. And he does not sweep the dust or remove the ice from the roof, because dust and ice are meant to be there and he has no authority to change the balance of things. Living by himself in the woods he finds peace.

It is significant that the only person who becomes his friend is the Twymans' daughter Belle who does not speak. She is deaf and they use non-verbal communication. Joseph finally finds a person who understands him with no spoken words that have got him in trouble for so many times. He and she are outcasts in their societies. They find each other in the middle of the ocean and keep in touch hidden by woods. The author constructs this situation of phenomenal friendship and understanding where the words are not as significant for getting to know each other better.

"He realizes he does not know how to talk about his mother, he has no words for it" [175]. It is another example of words not being able to convey the most important, as well as Joseph's interesting observation about whales' "speech" that consists of "clicks and creaks and clinking like bottles being smashed together" [174]. This is one of the 
distinct features of this story - an outcast who does not find his place in human society, does not relate to one of its major attributes which is human language and spoken words. His mother forced him to study the dictionary knowing that this way he hopefully would be able to communicate and survive, but his only friend does not need to hear his words, and whenever people have spoken to him something bad happened.

There are outcasts, those who cannot find their place in the society or whom the society rejects. But, as Joseph finds out for himself, things are immensely interdependent. "When things vanish, they become something else, in death we rise again in the blades of grass, the splitting bodies of seeds" [174-175]. And being away from people he learns how to sense this connection, without words. The need of taking care of nature that protected him from the cruelties of the society is very acute for Joseph. He remembers the whales whose hearts he has buried and thinks about them: "One of the whales... lived longer than the others. People were tearing skin and fat from the dead one beside it. It watched them doing it with its big brown eye and in the end it beat the beach with its flippers, slapping the sand. I was as far away as the house is from us right now and I could feel the ground shaking" [175].

Joseph is discovered by Twymans and taken to police for trespassing after they find out that he, who almost destroyed their house because of his negligence, is still hiding on their territory and, what is even worse, communicates with their daughter. By the time it happens, Joseph's garden that he started in the woods has brought its fruits and he has shared the most sacred memories with his friend Belle. He accomplished his mission of allowing the hearts of whales to come back to life as fruitful plants that he grew in the soil which covered the buried hearts. Joseph also learned that he found home 
only by losing his house and family and becoming an exile from wherever he had tried to become a part of. He found himself and his attachment to the nature, and he came to the conclusion that the main lesson he learned is that nothing should be wasted, and every little element is important in the chain of life. "If I had to do it over again, I'd bury the whole whales. I'd sow the ground with bucketfuls of seeds... I'd let the weeds grow and the ivy, everything would grow, everything would get its chance," he thinks [180]. Even the weeds, even something that normally people would pull out of the ground and throw away, would be given a chance. It is a moving analogy for his own life, himself being a weed in the society that rejected him, and a hint on the importance of Joseph and his work for the balance that other people neglect because of their arrogance and lack of wisdom.

Leslie Marmon Silko created three central characters who represent the diversity of minorities in her work Tony's Story. The main character, Tony, is a young Native American, who lives in an Indian reservation. His cousin Leon is a Native American as well, he has returned to his home town after the service in the military. The military service has changed Leon and now he does not follow the traditions of Native Americans and their beliefs but at the same time he is not treated as equal by white people. The third central character of the story is a white police officer who does not leave Tony and his cousin alone. He is a "bad cop", a racist and a vigilante who works in the reservation where he is a minority among Native Americans.

The plot that brings three outcasts together from the very beginning of the story promises a conflict with a tragic outcome. The symbolism of dying is present in all the descriptions of nature, creating an atmosphere of the inevitable death. "The sheep were 
thin, and the tumbleweeds turned brown and died" [579] is the opening description of the summer when the events of the story take place. The story begins when the day is coming to its end as well: "The sun was dusty and low in the west" [579].

The reservation where the characters live has a very unusual combination of traditional elements of Native American customs and stereotypically American mass culture. Globalization that invaded the village has been changing it, but even though the locals eat hamburgers and drink wine, while their children cry for more Kool-Aid, their beliefs in totems and spirits are still strong. Leon made a step further. Once a local, he spent several years in the US army and after he returned the changes, that his personality has undergone, annoy Tony. He notices all the signs of whiteness in his cousin "He yelled at me, "Hey Tony - over here!" I was embarrassed to hear him yell so loud" [579], and "He grabbed my hand and held it like a white man" [579]. Not a slightest detail of Leon's changes escapes Tony's attention. These changes irritate him, and he simply does not understand many of them. To treat his cousin Leon gives him a dollar: "Take this dollar - they're selling hamburgers over there" [579]. But the plans for entertainment are interrupted by a white policeman who approaches them and without saying anything hits Leon in the face with his fist. Later in the text the policeman explains everything very clearly to them: "I don't like smart guys, Indian. It's because of you bastards that I'm here. They transferred me here because of Indians. They thought there wouldn't be as many for me here. But I find them" [582].

In her work Listening to Ghosts: An Alternative (Non)Argument, Malea Powell, a scholar of Native American culture and history, points out: "Newly arrived European colonists brought their own "myths" about the order of the universe; their continuous 
contact with what they saw as "primitive" cultures ensured that the colonists would be preoccupied with defining for themselves and for others the nature of their relationship with "other" [Powell, 17]. And as she elaborates further, the centuries have passed but not so much have changed in that mode of relations and communication.

Ironically Tony does not feel that his cousin Leon is still like he used to be, that he became different, but the police officer hits Leon because he is Indian. "He can't do it again. We are just as good as them" [581], Leon complains but it only makes Tony think again about how hopelessly different his cousin became, that "all the guys who came back always talk like that" and he is now just another one of those troublemakers who mess everything up. Tony does not believe in rights that his cousin is constantly talking about. Ever since that incident, the policeman seems to follow Tony and Leon everywhere. They run into him on the highway, he happens to be at the gas station when they are there too. The officer's dark sun glasses which he never removes and his uniform dehumanize him in the eyes of Tony, and the inevitability of being followed everywhere makes Tony suspect that the officer is not a man. He has nightmares about the officer pointing a long human bone at him. In his dream, the officer's whiteness glows in the night and his face resembles a demonic ceremonial mask with white-rimmed eyes. "But if he really was what I feared, then he would not need to see me - he already knew we were there" [580], as Tony shares his concerns after running into the officer on a new occasion.

In Tony's understanding, his cousin has lost his true identity. It is the white culture that changed his cousin, and it is white people who are invading the life of Indians. Everything related to white Americans frightens Tony, he naively attributes 
superstitious powers to the white police officer. He tries not to look at the policeman like when he was very little he would not look into the masked dancers' eyes so they would not grab him. Even in the dark, when the officer's face cannot be seen from the distance, Tony notices the silvery lenses of the dark glasses worn by the policeman all the time. The inability to see the eyes of a human on the policeman's face becomes another point in the support of Tony's idea that there is something more to it, that the policeman is evil. "I knew that the cop was something terrible, and even to speak about it risked bringing it close to all of us; so I didn't say anything" [582]. Unfortunately, all his beliefs and fears can be explained in a much more pragmatic way. The officer is just a racist. He has no superpower besides his gun, his stick and his hatred towards Native Americans in combination with the abuse of the power given to him by the state. But throughout the last quarter of the text Tony is already persuaded that their lives are in danger because a demon is following them, and he no longer refers to the officer as "he", now Tony uses the pronoun "it". "There is no place left to hide. It follows us everywhere," and "We've got to kill it, Leon. We must burn the body to be sure", he says anxiously [583]. Now he knows why the drought had come that summer, he cannot help noticing that it has not rained for a long time, and even the tumbleweeds are dying. He is worried that even a gun would not protect his cousin and gives him an arrowhead on the piece of string to wear it around his neck for protection. Leon does not believe that Tony is being serious about all of that: "Have they brainwashed you into believing that a .30-30 won't kill a white man?" [582].

The next Tony's encounter with who he thinks is "It", happens to be fateful for the police officer. The policeman tells Leon: "You made your mistake, Indian. I'm going 
to beat the shit out of you". He raised the billy club slowly. "I like to beat Indians with it" [583]. The image from Tony's nightmares comes back, even though the officer uses a club instead of a human bone and the mirror-lenses of his glasses hide human eyes behind them, and Tony shoots the policeman to death. "It's killed. They sometimes take on strange forms," he says [584].

If in the story Caretaker two outcasts find each other and become friends, Tony's Story shows three outcasts who suffer from the insecurities of those who they cannot relate to. It is significant that even though the police officer hates Native Americans, he picks the most Americanized among them for his attack. Leon believes that he has equal rights with white people, he acts like a white man, and that is what attracts officer's attention who says that he hates smart guys like him. On the other hand, Leon's behavior annoys his cousin who sees significant changes in him after being in the army. Leon is no longer a stereotypical Native American but he is not a white man either. It is similar to the ideas expressed by a queer theorist E. Patrick Johnsons in his article Mother Knows Best when he compares gay community with African Americans: "It's like black people who try to act white. No matter how much they try to get away from who they are they are still black. And most black folk will still claim them even if they don't claim their blackness" [Patrick Johnson, 260]. In other words, both the officer and Tony are subject to the same insecurity of losing their self identity. The officer is annoyed by the fact that one of the Indians, which he hates, can imagine that he has equal rights with a white man. Tony is frustrated about the fact that his cousin is no longer a Native American and that he has lost his routs and beliefs for the sake of values of white men who have brought nothing but evil to their people. His cousin though is still closer to him, he is his relative, 
but the police officer represents the ultimate evil that haunts them everywhere and puts their lives at risk. Tony's hatred towards the white man who does not belong to their reservation but harasses them is based on his fear of death, both physical and cultural, because people like the white officer have changed his cousin and their traditional way of living, endangering their identity. Killing the officer, Tony kills the deathly evil coming from white people that this officer signifies.

Even though discrimination based on race, ethnicity, religion are unacceptable, they can still be easier comprehended and explained when one takes in consideration the complex of historical perspective, cultural differences, conflict of beliefs and values. This model can be simplified to something similar to playing for opposite teams in sports where you need to win in order to survive.

The next group of marginalized characters though is represented by people who become outcasts in their own families when they are alienated by those who are expected to love and take care of them. 


\section{The Disowned}

One of the common features of the marginalized characters is that they usually represent fears of those who outcast them. But at the same time, those, who genuinely support them or learn how to find a peaceful way out of the differences between themselves and those who they could not accept, tend to learn something important from them. Most often it is a realization of shame or triumph over fears. The combination of shame and fears is the strongest when the outcast is one's child, different from what he or she was expected to be, when a child fails his or her parents' hopes or merely does not conform to their notion of what the acceptable norm is.

In Amy Bloom's story Silver Water, there is something more than just parents' disappointment because their daughter did not become somebody they would be proud of, the child happens to be seriously sick. As a little girl, Rose surprised her family with her gift of a beautiful opera voice. "Her voice came out so crystalline and bright, that all the departing operagoers stood frozen by their cars, unable to take out their keys or open their doors until she had finished and then they cheered like hell. That's what I like to remember" [72], recalls her sister Violet who actually is the narrator of the story. This memory introduces that the girl had a big potential in the childhood and had good chances to become a child who many parents would be proud of. But at the age of fifteen Rose had her first nervous break. She became easily depressed and eventually stopped coming home, when her mother would have to go into the woods behind their house and bring Rose home. Girl's parents do not have the same attitude to what is going on with 
their older daughter. While Rose's father has the opinion that they need to talk more with her, dedicate more time and just be closer, Rose's mother responds "David, she's going crazy, she doesn't need a heart-to-heart talk with Mom, she needs a hospital" [73].

When the father, who is a psychiatrist himself, is asking his colleagues to drop by their house so he can show Rose to them, Rose's mother is occupied with what is the most important to her at this moment, she packs her "crazy" daughter's suitcase, ready to take her in the car and drive away. Possibly such difference in two parent's reactions can be explained by their professions. Even though the father is psychiatrist, he cannot make any objective conclusions about his daughter, he is also in a denial of the possibility of him not being able to notice any traces of mental disability in his own daughter on time, and now she is about to become one of the disabled people who he sees every day at work as his patients. The mother, who is a professional musician, is certainly aware of the fact that her daughter will never become an opera singer, at least unless she is treated properly by doctors. Mother's pragmatism in this situation seems to be almost cruel. There is no evidence of her showing any degree of compassion to her sick child in the text, because if she really was concerned about Rose's seeing a doctor as soon as possible she would at least wait for her husband's colleagues to have a look at their child. Instead, the mother rushes to get Rose out of the house as fast as she can, and there is an explanation to this. They have Violet, the younger of the two daughters, who lives at the same house. Violet does not show any symptoms of mental disabilities and, as the narrator, she recalls her fears and how the last thing her mother did before leaving with Rose was offering the encouragement: “It won't happen to you, honey. Some people go 
crazy and some people never do. You never will', she smiled and stroked my hair, 'Not even when you want to" [73].

But what makes the mother so sure that her other daughter will never "go crazy"? Is it what she hopes to achieve with the sacrifice of isolating her sick child from the healthy one? Apparently, the mother's main concern is not really to help the daughter who is disabled but to make sure that the other one stays normal, according to her understanding of norm.

Even though girls' parents are trying to do their best for the family finding funds to make sure Rose can stay in the clinic and keep another daughter at home, safe and close to them, they are lacking the most important part of the relationship between parents and children, they do not really know either of their daughters. Dr. Thorne, Rose's therapist from Texas whose nickname is "Big Nut" happens to grasp the core of Violet's personality the first time he meets the whole family. "He christened us all, right away... No One's Nut - a name which summed up both my sanity and my loneliness" [74]. Dr. Thorne calls Rose "Darling" and he manages to establish trusting relationship with his young patient. Further in the text the narrator confesses: "I went back to college and found a wonderful linebacker from Texas to sleep with. In the dark, I would make him call me "darling", [75]. The doctor is a stranger to the family but he finds a way to help the narrator's sick sister feel comfortable in his clinic, he also becomes a figure whose care is so significant to the narrator that she is looking for something similar in her relationship with her boyfriend. Dr. Thorne, maybe due to his professionalism, is the only one who, unlike other therapists and even the family, treats mentally challenged Rose as his equal. 
After five good years Rose's doctor dies, her condition gets worse. Her new psychiatric coverage wouldn't begin for forty five days what makes her parents take her home. Again, the mother insists that Violet, the healthy daughter, stays away from home during the weekdays because she does not feel safe about it. It does not make much sense because Violet is a grown- up who teaches at a college, she is no longer a child whose psychic is still immature and who a paranoid parent would need to isolate from any kind of harmful influence. The narrator describes this period, "I stayed away until Sunday, afraid to pick up my phone, grateful to my mother for her harsh calm and her reticence, the qualities that had enraged me throughout my childhood" [76]. The parents do not want to tell Violet that her sister's condition is getting worse and that they do not know how to handle it, how to approach their sick daughter who has not been out of the clinic for years. Rose breaks the furniture, she is paranoid, she bangs her head against the kitchen floor and shakes her mother off badly when she is being restrained from harming herself. This situation is so unbearable for the family first of all because they do not know how to handle it. They are not used to dealing with it, because concerned with their healthy daughter's well being they completely alienated the one which is not as healthy to the extent that they do not even know her anymore. Though Rose is the one who feels guilty: "Oh, Vi, Mommy, I'm sorry, don't hate me" [75], she repeats. And after the dinner she wants to go to bed right away. "I want to go to bed. I want to go to bed and be in my head..." [78]. Does to "be in my head" mean that she wants to sleep, or is it her way to say that she cannot be where she is. The family home is not the home for her anymore, and she needs to be somewhere else, to escape. 
The narrator's description of what the mother is doing after Rose is being taken to bed by her father says a lot about the mother's personality. "We cleared the table without talking, my mother humming Schubert's "Schlummerlied", a lullaby about the woods and the river calling to the child to go to sleep. She sang it to us every night when we were small" [78]. The mother does not take her daughter to her bedroom, the father does. She does not sing the lullaby to her daughter either. Rose's mother is still humming it though while cleaning the table. It is not her daughter who is dear for her, it is her memory of what it was like when the girls were still small and both still healthy. She loves her Rose but not the real Rose. She loves her memories about her daughter when she was like other children, even better than other children with her beautiful voice.

That night Violet finds out that Rose is not in her bed, and Violet knows where to look for her. She finds her sister in the woods and witnesses her uncovering the bottle of white pills, though she does nothing to stop her sister. Violet stays with Rose watching how she commits a suicide. By the time she comes back to the house their mother is standing on the porch. "My mother was standing on the porch, wrapped in a blanket, watching me. Every step I took overwhelmed me; I could picture my mother slapping me, shooting me for letting her favorite die" [79].

Though, again, Rose was not her mother's favorite, neither was she of her mother's major concern, until Rose died. The mother could not stand her presence in the house and did not know how to deal with her daughter who had to be in the house for forty-five days while "she hasn't been symptom-free for forty-five minutes" [77]. The mother only cherishes her memories of Rose when she has not been sick yet. She keeps living with her dreams of what her daughter could have become in the future, granted she 
had a beautiful voice. "I raised warrior queens", she says, when she learns that her younger daughter witnessed Rose killing herself. But this title is earned by Rose only in her death, after her sacrifice. While she was alive and sick, she was referred to as "crazy". The mother made efforts to get her abnormal daughter treated, and when the treatment proves itself to be unsuccessful, Rose is let go. The situation in Rose's family reminds most of all of natural selection where the weaker must die in order to let a stronger child survive and be healthy. Violet, as the stronger child, survives and Rose is no longer an obstacle for normal functioning of the entire family. Rose was allowed to die, so the family can get rid of the reminder of sickness and the mother now has only one daughter whose mental health is not threatened by her sick sister's presence. Also, Rose cannot be any more a constant reminder of unsuccessful parenting and the dead end of the family tree, almost never present in the family but still being always a constant burden.

This pattern in parental behavior is very similar to the attitude of a father about his son in Greg Hrbek's Sagittarius. The analysis of the father's motives in Greg Hrbek's story helps to understand the reasoning of Rose's mother. The way Susan Sontag found a reason for not giving her sick character a particular name or any particular face, so he would represent all sorts of people afflicted by the disease in The Way We Live Now, resembles Greg Hrbek's choice of the child's deformity in his story. Instead of attributing any particular deviation from a norm to Sebastian, Mr. Hrbek takes an allegorical approach to the boy's difference from others and creates a character who is a Sagittarius born in an average middle class American family by an ordinary married couple.

When Martin and Isabel visited a doctor and conveyed the ultrasound analysis of their soon to be born baby they are presented shocking news. Not only their son would 
never be able to walk but his deformity is so strange that the medical personnel of the hospital do not dare to identify what exactly the diagnosis is and how they would be able to fix numerous problems that the baby would be born with. In fact, when Sebastian is born his life is absolutely not in danger, the major concern of the family and doctors is that they cannot identify what is wrong with the boy. He has four legs, with hooves instead of feet, and only his upper half looks human. This becomes a tragedy for the family, because they now see that the ultrasound was not inaccurate, that whatever it showed turned out to be reality that they can no longer deny. Even though the doctors did not expect Sebastian to be able to walk, the opening scene of the story depicts Sebastian's escape from the house into the woods.

What makes Greg Hrbek's story unique is that he creates this allegory of an average in all aspects family that happens to have a mythological creature as their child, an abnormal child in a normal family. He uses definitions that create the feeling of being introduced to something strange and ill when we see the boy from his parent's perspective. "The unit was one large room, very quiet, full of incubators that made her think of aquarium tanks, then display cases, then - because they were wheeled and curtained - of something else she couldn't quite put her finger on" [111]. This description is taken from the scene of Isabel, Sebastian's mother, going to see him for the first time after he was born. She does not know what her son looks like yet, but from what she has learned from the doctors she is prepared for the worse. Her anxiety makes her think of incubators and aquarium tanks, as if she is about to see an odd animal rather than a child, something deathly that would be scary to even touch. At the same time, the author describes the boy from his own, neutral and that is why more accurate, perspective. From 
the very beginning of the story it is clear that the boy is healthy, because he is strong enough to walk and run, his body does not cause any inconveniences to him except for it does not allow his parents to see beyond his appearance what creates a big gap between them. And this physical difference can apply to many scenarios of children being not like others, not what their parents would want them to be.

What exactly creates the problem in the situation of this family? For many months they have been thinking of what their son would be like, they are surrounded with magazines for parents with "those airbrushed cover photos, those mirages of flawlessness" [109]. Flawlessness, correctness, and "wrong" are the words that become the most important in the vocabulary of their conversations with the doctors after their son is born. The father's thoughts keep bothering him "The fact is, no one knows exactly what's wrong with his son. No one knows what he is" [109]. It is not the matter of boy's health, but it is the troubling lack of definition that makes the parents worry. Further in the text the same concern is expressed by the boy's mother, Isabel: "There is a name for what he is. Why can't she think of it, why can't anyone think of it?" [110]. It is not the first time she is thinking about this problem that they cannot solve, in fact her first thoughts of the baby were very similar: "She didn't yet understand what he was. Was there no word for him, or simply no cute word, no word that didn't invoke a darker age? She was afraid" [111]. Nevertheless, the boy has been developing and growing since then and nothing seems to bother him but what is still frightening is this absence of a correct term, a word that would be attributed to Sebastian and officially make him something more or less human, and known by medicine. What is unknown frightens. There is though a person who figured everything out right away. In his child's innocence 
Sebastian's three-year-old brother says what he sees and calls his brother a foal, an observation abruptly denied by the father right away.

This denial of the reality stands out in the text for several times. "She could no longer deny the truth" [108] is said about Isabel, but the father cannot admit to himself that there is nothing to be possibly done in this situation. This pattern reminds of a dialogue between the parents of Rose in Silver Water: "After three weeks of this, my mother, who is a musician and widely regarded as eccentric, said to my father, who is a psychiatrist and a kind, sad man, "She's going off."/"What is that, your professional opinion?" He picked up the newspaper and put it down again, sighing" [Bloom, 73].

As a matter of fact, the parents' attitude to their son's condition becomes different as soon as he starts walking what actually proves the doctors wrong for the first time in this story. It gives Isabel hope, she understands that her son is different, but at least he is not suffering, what is certainly not enough for Martin. When Martin sees their disabled son standing on his four legs, his initial reaction is happiness, but then something draws him back and he insists that they can't let Sebastian do this, because he will get used to standing like this and they "won't be able to break him of the habit" [112]. Standing on four legs is a bad habit in the father's opinion because he cannot think outside of the framework of his understanding of norm. Normal children do not stand on four legs that is why standing on four legs is a bad habit according to his understanding of standards. What he fails to keep in mind is that his son was not born with two legs like other children so he cannot be expected to do what other children do when they walk. The mother's feelings about the boy's "deformity" slowly change throughout the text though. Sebastian's ability to walk is what makes her happy for him, and the surprising news is 
all that matters to her. That is why she cannot understand Martin's disappointing attempt to stop the boy from walking like this: "You just wish he'd go away, she said too loudly. Not just half of him. All of him" [112]. Ironically, such description of Sebastian's father's feelings about him resembles the feelings of Rose's mother in Silver Water who first of all made sure that her daughter would not be in her home and then later even allowed herself to be a passive bystander of her daughter's suicide.

The father's struggles with his son's appearance make him think of incredibly awkward solutions of what he perceives as a problem. "Martin can barely admit it to himself, but his wife is right. He does sometimes wish the baby would disappear. Not half of him. All of him. Now it's happening" [114]. Even when they finally find their disappeared son, Martin cannot get rid of his thoughts of Sebastian as of "his strange son", this adjective is always attributed to the boy in his thoughts about him. It is critical to understand that there is obviously something going on besides the concerns about the boy's well-being. His mother has already accepted him: "Not like other boys. And not entirely human. But why all this grave talk of abnormalities and deformities, when anyone can see he is exquisitely formed? A beautiful boy from the waist up, and from the waist down, a beautiful horse..." [116].

There is one important hint in the text to the core of the problem in the situation for the father. And the problem is not about boy's suffering but it is in father's selfishness. "He [Martin] just wants him [Sebastian] to be normal. He wants fatherhood to be free of pain and paradox" [114]. This explains why Martin does not call local police to notify them that his son disappeared. He justifies it very simply, saying that there is no way for him to give the description of the boy and be taken seriously by police, but in 
reality it is his shame. He does want his son disappear because, exactly like the father in Silver Water, he will not be associated with a sick child anymore. Nobody would be able to even think that he somehow failed and did not fulfill the expectations of being a successful parent. This feeling of guilt about having a child who is different in both stories becomes so overwhelming that the parents are ready for the most nonsense solutions just not to be thought of as of a parent of an abnormal child. This anxiety about not meeting the expectations of the society make parents in both stories detach and alienate from their children. The shame prevails over their love. "He's careful to keep his voice free of anger so his son will not misinterpret his intentions. I don't want to punish you, I just want to help" [107]. But it is not the son who may misinterpret the father's intentions. It is the father himself who misinterprets the true motives of his behavior. In fact, he is angry at his son, at entire situation, and he does not want to help, but he wants to fix his son and fix the problem of his shame. Sebastian is the reflection of his father's manhood which in the eyes of the society of a small town would definitely be interpreted as his failure of being a man. He failed to give a birth to normal posterity. Even if he cannot actually help his son, he can still try to make it look like his son is normal.

At first, he hides the boy in the house, but as Sebastian grows it becomes harder and Martin starts contemplating unthinkable surgeries that would help to hide his boy's "deviations". "If it were up to Martin alone, the surgery would have been performed long ago. The forelegs lopped off. After that, an operation to alter the angle of the femur, another (involving the embedding of metal hooks and wires) to straighten the spine. Six weeks in cast. Then laser hair removal. Genital reconstruction. The doctors call it medical necessity. He can't stay like this. He will never walk. He never will - But he is" [117]. 
But there is some hope for the father to change his opinion. His voice is stronger in the family but Isabel's understanding of her son did not happen right away either. Before she realized that they can get through this together, her thoughts of the boy were similar to her husband's. She also used to think that her son's almost improbable condition was a bad dream and that it was about her rather than about her baby. In the beginning of the story her perspective was similar to Martin's: "But every thought of him feels somehow like a thought about herself. As if there's still a cord strung between them, a useless cord that links them but doesn't keep them connected" [107].

Only in the very end of the story there is some change in the father. Something serious is revealed to him when he finds Sebastian in the woods where he seems to belong better to than to the society upon the standards of which his father judges him. "Ever since the birth, Martin has been praying he'll wake up. Wake up to find that the world is really a mundane place. Now, under the zodiac sky with this infant, he sees the absurdity of the notion; and with a trembling inside, he thinks to turn away from it" [117]. Such understanding of the category of norm not applying anymore comes to Martin only when he sees his son from a new perspective, outside of the society with its compulsory norms and understanding of one having to be like others in order to be accepted. Such understanding refers us back to The Caretaker by Anthony Doerr where the characters could find themselves only outside of the traditional social expectations, in the nature, where they would not compare themselves with any established orders, and where they finally understand each other even better without traditional means of artificial languages, speaking the language of their feelings not restricted by the deafness of one and poor vocabulary of the other. 
The summary of the analysis of the two stories about different, abnormal, children alienated by their parents reveals similarities and common patterns in both stories. The parents of both Rose and Sebastian do not want to admit the truth about their children at first. They live in the denial. When the realization of the reality happens, the first reaction is an attempt to get rid of the sick child or thoughts about how easier the life would be if the child was lost what is explained by fears and anxiety about the burden that a family is not ready to handle. Both couples of parents have big expectations about their children before they face the fact that the child will never be the realization of their parental dreams. The combination of guilt and shame in both cases forces the parents to alienate their children, to pretend that they have nothing to do with each other. They see their abnormal children as a failure of themselves as parents who did not succeed in having healthy posterity, what means that their children will not happen to continue the family tree. The importance of medical treatment in Silver Water is predominated by the desire to send the girl away from home and from her healthy sister, in Sagittarius the father knows that there is no need in surgeries but he wants his child to look normal. Neither of the stories show that parents want their children to be treated for the sake of the children's health, at least it is not the major concern in either of the stories. Parents' selfishness prevails over compassion to different extent in the stories. In case with Rose it results in her death, in the story about Sebastian his parents in a hard way of almost losing their son because of it learn how to accept him.

Silver Water and Sagittarius are stories about different children with very distinct similarities. They describe parents whose motivations can be explained by their fears which happen to be stronger than their care about their child. In the first story, the 
mother's main fear is that her healthy child's life will be affected by the presence of the sick sibling. But according to the narrator, their mother is not any closer to her than to Rose, she is also a "No One's Nut" as the doctor christened her. It is questionable whether the mother is so concerned out of her care for the healthy daughter or because she needs to make sure that she has a healthy child. Like in Sagittarius, where the father even admits to himself that he wants his son to be normal and that he should have insisted on various surgeries to make his son normal and his fatherhood free of pain and paradox. It should not be painful at least because the boy is only different, he does not suffer from anything and his condition is perfect for a half human half horse. The paradox for the father is painful because his son obviously does not resemble him. To narrow it down to the essence of the problem both characters are at fault because they cannot fulfill their parent's need for having healthy posterity and their hope that after their physical death they will live in their children and further healthy generations. Their fear is a fear of death in its very strange and twisted form.

The idea of necessity to have healthy children so one can live in further generations is developed more elaborately in T. C. Boyle's story Caviar where inability to have children becomes the reason for a family to fall apart. In this story, husband and wife are doing everything possible to find a solution for their problem, and they hope that having children will make their family stronger and happier, but they do not know that when they find out which of them is unable to have children it will become the reason for jealousy and anger with the other partner.

Besides explicit conversations of the main characters of the story about their hopes and unsuccessful attempts to make having a child possible, the text has a variety of 33 
allusions to procreation, infertility and death. This symbolism is implied even in the title of the story. The narrator and his wife Marie are the first one in the area where they live "to have a baby this new way", by artificial insemination with the help of a surrogate mother. It took them years to find out that Marie is unable to have children of her own, and all this time the couple does not know why all their attempts to get pregnant are in vain. Images of death follow them. "Crocuses and dead man's fingers were poking through the dirt along the walk" [80], "I'd come in off the river, reeking of the creamy milt and silver roe that floated two inches deep in the bottom of the boat while fifty- and sixty-pound stripers gasped their last" [81]. When they go to the Coptic Brotherhood to find help there, the conversation with a nun looks like a parody of their difficulty: "I listened to Marie explain our problem and watched the crescent of egg on Sister Eleazar's face fracture with their smile" [81]. The milt and roe on the bottom of the boat, and cooked egg on the face of the nun who later recommends them to eat soup with components like roe and goat milk or use mustard (which is a condiment made from the seeds of a mustard plant) are just a few examples of seed and ovaries that are wasted throughout the text of the story. "I was reading about the dead water between Manhattan and Staten Island - nothing living there, not even eels" [87]. While in the nunnery, the narrator observes what is on the land further: "A man with a hoe was digging at his garden in the next yard over" [82], as a reminder of somebody working hard to help the seeds take.

After seeing a doctor, the couple finds out that the problem is in Marie and their only chance to have a child of their own would be to use the help of a surrogate mother. Surprisingly, the news is not seen by the husband as upsetting, instead he has very selfish 
thoughts about it. He is almost excited thinking: "She was the one, she was defective, not me - bursting to exercise my God-given right to a child and heir" [84]. Even though originally it was Marie who came up with the idea that they needed a baby, the narrator becomes preoccupied with the idea. Because now he knows that his wife cannot fulfill the desire of having a child but he can.

When the doctor performs the procedure on Wendy, the surrogate mother that the doctor found for them, the narrator thinks: "I felt humbled somehow, respectful in the face of life and the progress of generations of man: My seed is going to take hold, I kept thinking, In half an hour I'll be a father" [86]. Since this moment the narrator always refers to the child as his son rather than their son in his thoughts.

The importance of having his own son for the narrator is understandable and at the same time it very well illustrates one of the reasons why homosexual children are not easily accepted by their parents, especially fathers. As E. Patrick Johnson describes the situation: "Homosexual sex announces the death knell of the father's desire for (biological) grandchildren and wish to pass along the family (i.e., his) name. It means the loss of his son because of the ways in which AIDS is thought of as a gay disease" [Patrick Johnson, 262].

Eventually the narrator even comes to a point when he doubts where he still loves his wife: “Wasn't Wendy as much my wife as Marie? Wasn't marriage, at bottom, simply a tool for procreating the species?" [88]. Judith Butler's concerns about the compulsory reproductive role of a woman has already been mentioned above. And Butler is not the only one who mentions it in her works related to marginalization. Adrienne Rich writes in Compulsory Heterosexuality: "It would seem logical to pose the following questions: 
why species survival, the means of impregnation, and emotional/erotic relationships should ever have become so rigidly identified with each other; and why such violent structures should be found necessary to enforce women's total emotional, erotic loyalty and subservience to men" [Rich, 232].

The narrator's fantasies about his soon to be born son and the woman who carries him in her womb slowly creates a gap between him and his wife Marie. He even allows himself making plans that he knows will never be realized, morbidly cruel dreams: "Wendy and I would take the bus for California, then write Marie to come join us; we'd fly to the Virgin Islands and raise the kid on the beach; Marie would have an accident" [89]. Such imaginings remind of Rose's death in Silver Water, and the father's hopes that Sebastian would disappear in Sagittarius. This is a necessity for somebody who is unable to give birth to get out of the way and not be an obstacle for the process of procreation and progress of generations that the narrator reflects on. In Eve Kosofsky Sedgwick's introduction to her research Tendencies, the author expresses concerns that are familiar to her not only from fiction, but from the everyday work and life experience. Her words can highlight the main conclusion of the present chapter: "Seemingly, this society wants its children to know nothing; wants its queer children to conform or (and this is not a figure of speech) die; and wants not to know that it is getting what it wants" [Kosofsky Sedgwick, 3]. 


\section{Marginalized by Outcasts}

The third type of marginalization is probably the most interesting. It includes the discrimination of the different characters by other characters which are actually marginalized for the same exact reason.

The story by Reginald McKnight, The Kind of Light That Shines on Texas, is an example of not very traditional approach to the problem of racism. This is a story of the narrator's childhood as a black boy in a school where all children and teachers were white except for three students. Clinton was one of those black children. The unusual feature of this story as that the narrator recalls how much he disliked the other black boy in his class. The events of the story take place in 1960s, and even children who are friendly do not realize how racist their questions and commentaries may be.

Clinton's main enemy in school was the boy named Oakley. Oakley was a white boy, a couple of years older than him, who kept picking on him and sought for any reason to beat him up. And even the main conflict in the story is going on between the white boy and Clinton, all the narrator's descriptions of Oakley and other white children are lost in comparison with how much attention he pays to the ways and reasons he did not like the other black boy in the class who never did any harm to him. These memories about him actually open the story. "I never liked Marvin Pruitt. Never liked him, never knew him, even though there were only three of us in the class. Three black kids" [386].

One of the major difficulties for Clinton in school was that his teacher, Mrs. Wickham, was racist too. "Wickham didn't like us. She wasn't gross about it, but it was 
clear she didn't want us around. She would prove her dislike day after day with little stories and jokes" [388]. In such atmosphere it was very difficult for the boy to be different, to know that the teacher's jokes related to him, and to hear his classmates' seemingly innocent questions about his hair and whether he washes and combs it or he does not need to. Clinton was not comfortable about being the center of attention and pretending that his teacher's jokes did not hurt him. He developed a feeling of shame about being associated with other black children who were not active in class. After all, the color of his skin became the reason for Oakley's attacks on him. And Clinton is not as much upset because of the difference between him and others as because of being black like his classmates Marvin and Ah-so.

He tried to ignore his difference from other kids and earn his teacher's respect. "I, myself, would smile at Wickham's stupid jokes, sometimes fake a laugh. I tried to show her that at least one of us was alive and alert, even though her jokes hurt. I sucked ass, too, I suppose. But I wanted her to understand more than anything that I was not like her other nigra children, that I was worthy of something more than the nonattention and negative attention that she paid Marvin and Ah-so" [388]. That is why the fact that he belonged to the same race as the other two children did made him unhappy. He thought that his was treated differently because of them, because kids like them were the reason of his undeserved bad reputation and prejudice towards him by association.

He saw only the worst in Marvin: "He embarrassed me. He smelled bad, was at least two grades behind, was hostile, dark skinned, homely, close-minded" [386]. The description of Ah-so appears very often in the story too. One of them is: "Ah-so was big, thick, and African. She would impassively sit, sullen, silent as Marvin... I never spoke 
one word to her, nor she to me... I didn't despise Ah-so as I despised Marvin" [387]. It is quite interesting that in the lists of qualities with negative connotations about Marvin and Ah-so Clinton mentions "dark skinned" and "African". He also mentions a lot that they both were quiet and that he actually never talked with either of them. In one of the conversations about Marvin, their classmate asks Clinton if it makes him ashamed to be colored, and Clinton replies "No" and then adds in the narration: "But I meant yes... I was ashamed. Ashamed for not defending Marvin and ashamed that Marvin even existed" [389].

All these sorts of things made Clinton even more upset when one of his classmates explains to him the reason why Oakley never leaves him alone and threats him all the time with promises to bit him up after school. The classmate's explanation is "He don’t like coloreds" [392]. Desperately, Clinton responds to Oakley making a reference to Marvin: "How come you're after me and not him?" [393]. That was the question of his fears becoming truth, the question of Clinton's safety and survival in school. Also, that was the question that makes him, a black boy, no less of a racist than his angry classmate who keeps bullying him because of the color of his skin.

And one day the teacher explained to them how the reflection of light worked and that the whole multicolored world was not what it appeared to be, that the colors look like they do only because of the light that shines on them. Clinton recalls his thoughts that he had: "I wondered what kind of light I could shine on Marvin, Oakley, and me that would reveal us as the same" [395].

One of the most interesting and complicated relationships between the marginalized character and his environment can be found in Susan Sontag's short story 
The Way We Live Now, in which she managed to create a complicated evolution of feelings, motives, and reasons for her main character to be perceived as different by the people who are closest to him. All the characters besides the main one have names, and only he is unidentified what makes him a representative of all those who are afflicted by "the disease" which is not identified directly but is obviously what we know as AIDS. The story was first published The New Yorker, on November 24, 1986 when not so much was known about AIDS yet and not as many people have been reported to suffer from it as nowadays.

In the case of the main character of The Way We Live Now it would be important to analyze the situation in its development. At first, it is hard to call this character an outcast. He is surrounded with twenty six trustworthy and supporting friends. "...Lots of people came in the first week, and the Jamaican nurse said there were other patients on the floor who would be glad to have the surplus flowers, and people weren't afraid to visit, it wasn't like the old days, as Kate pointed out to Aileen, they're not even segregated at the hospital any more, as Hilda observed, there's nothing on the door of his room warning visitors of the possibility of contagion, as there was a few years ago" [587]. This very long sentence goes on and on further creating the feeling of a sporadic flow of observations, and concerns, and ideas. The characters throw their ideas in trying to assure themselves and other concerned friends that the patient, the main character of the story, will be fine. The author does not name explicitly what disease the characters are talking about but it is clear that they all are at risk because they all are related to each other through complicated links of relationships and romances. Also the symptoms and the timeframe of the events helps the reader realize that the main character's friends are 
concerned about the possibility of him being HIV positive or having AIDS, which they do not know much about.

Long, almost confusing, sentences that the author uses to describe how the characters are attempting to calm each other down in fact produce the opposite effect of growing panic. Also the combination of the facts that it is just the first week of the main character's hospitalization and a number of other patients who have been in the hospital longer and wish there were people who "weren't afraid" to visit makes the situation seem less optimistic than it appears to be at the very beginning of the story.

The main character's condition in getting worse by page and accordingly the ways other characters cheer each other up are less persuasive. Very soon Kate tells Aileen, "You really should go and see him, he'd be happy to see you, he likes having people visit, you aren't not going because you are afraid, are you" [587]. In addition to the use of punctuation that misses question marks and quotes, the author blends dialogues into one uninterrupted stream of narration which is barely divided into paragraphs. It makes the reading different and creates a disturbing feeling of chaotic thoughts, fears, and concerns. The big number of characters may seem overwhelming until the reader notices that each character has a name that starts with a different letter of the English alphabet (Aileen, Betsy, Clarice, Donny, Ellen, Frank, Greg, and so on). It produces an interesting effect of insignificance of the names themselves. As soon as the pattern becomes obvious there is no doubt left that each of the twenty six characters, one for each letter of the alphabet, half male and half female, of all sorts of sexualities, altogether make this We from the title. When this realization happens, the reader is no longer just a bystander of the events. 
The text is divided into very few paragraphs for a story of this length (fifteen paragraphs on thirteen pages). Each paragraph represents a new stage of the character's change. The first paragraph guides the reader through all sorts of symptoms and fears the main character has, the second one already describes him in the hospital, surrounded by his loving friends. In the third paragraph, the initial hints of fear make the first of all the friends detach and afraid to visit him. Now, the conversations shift from concerns about the main character to speculations about who he could have possibly contracted it from. Further, the doctor who does not limit his consumption of chocolate just so he stays more cheerful is described as "talking like some old fangled country G. P. who tells the family that tea with honey or chicken soup may do as much for the patient as penicillin, which might mean, as Max said, that they were just going through the motions of treating him, that they were not sure what to do or rather, as Xavier interjected, that they didn't know what the hell they were doing, that the truth, the real truth, as Hilda said, upping the ante, was that they didn't, the doctors, really have any hope" [588]. This chain of assumptions about the hopelessness of the medicine introduces the new stage of the characters' behavior what eventually helps the situation to start falling apart.

"He was complaining about how dreary the hospital room was, and how it was like being locked up in a motel room" [588]. The environment of the hospital has a peculiar feature of being alienated because of a disease - one is separated from other people by the walls of the hospital room. It is not a prison cell where a criminal who has done something wrong is isolated from the society, and a patient is kept in the hospital first of all for his own benefit, but not only. Sick people in some cases are kept away from others for the benefit of the society. Despite the fact that the main character of 
Susan Sontag's story is visited by his friends, he is already separated from them, they are in the situation of "patient-visitor" roles, and his friends do have a choice whether to make the visit happen but he does not. Even though they come over and support him, he is no longer one of them with the same rights and opportunities. "There was an uproar of laughter around his bed while he watched them in silence, eyes bright with fever, all the while, as Victor recalled, gobbling that damned chocolate" [588-589].

The main character is still alive but ironically the friends of his who just a while ago could not face the reality of the seriousness of his condition begin talking about their memories of him when he was healthy. "When Kate shuddered and tears sprang to her eyes and Orson inquired anxiously if he, Orson, had said something wrong, she pointed out that they'd begun talking about him in a retrospective mode, summing up what he was like, what made them fond of him, as if he were finished, already a part of the past" [589]. Such observation made by Kate is an example of the pattern common for many marginalized characters of different stories who become outcasts not necessarily because people hate or just do not like them, they may be loved and still alienated. As if some strange social mechanism allows people to love a person and yet under the pressure of circumstances detach from him or her, to discontinue treating this person as equal even though it may be done unintentionally. The ways these people become outcasts are usually complicated and they vary from story to a story, but in Sontag's story the seemingly good intentions of friends who care about their sick friend and visit him constantly do not make his alienation less painful and harmful. Many of the characters do not even realize that how they treat the main character clearly shows that he is already different from them. He is the other who does not belong to their group any more. 
"But don't you think, Quentin observed to Max, that being as close to him as we are, making time to drop by the hospital every day, is a way of our trying to define ourselves more firmly and irrevocably as the well, those who aren't ill, who aren't going to fall ill, as if what's happened to him couldn't happen to us, when in fact the chances are that before long one of us will end up where he is" [590]. This statement made by Quentin again invokes the dualism mentioned above, the opposition of "patient-visitor" relations which regardless of intentions do not allow the patient to be seen as equal, at least because the frequency of the visits does not depend on his will. He depends on his condition, his doctor's permissions and the good will of his visitors. And according to Quentin's words we can conclude that at least some of the visitors come to the hospital not as much to support their friend as to support each other and confirm that difference between the ill and themselves. They want to make sure that they are still in a better situation that someone who has already been diagnosed with the disease. The disease that the main character is suffering from in the story, and in this particular time of the described events, is an imminently mortal one. In other words, at least one of the characters, Quentin, admits that seeing his friend helps him to make sure that that he himself is not as close to death, at least not because of the disease which each of the characters in the story were exposed to and have good chances of being afflicted by.

The awareness of the threat being present sips through the dialogues here and there in the text. "Since we are healthy, healthy as we can be; so far, Ira said" [591]. This kind of "healthy so far" remarks are present more frequently in the text as the condition of the main character is getting poorer. "When you say hospitable, Jan, I hear hospital", Hilda says. "In a way he's fortunate, said Yvonne... no one's afraid to hug him or kiss 
him lightly on the mouth... people who would seem to be not even remotely at risk are just terrified, but I'm impressed by how cool and rational you all are" [592]. But the characters are indeed terrified. Quentin finds it hard to read, Kate calls their friendship a pathetic utopia, Lewis admits to Yvonne that he feels quite hysterical, and Tanya believes that each of them in their fashion are having the disease what Ellen replies to as "everyone is at risk, everyone who has sexual life, because sexuality is a chain that links each of us to many others, unknown others, and now the great chain of being has become a chain of death as well" [592]. As Leo Bersani put it in his chapter of Intimacies, "Perhaps inevitably, AIDS infects sex with a consciousness of death" [Bersani, 38]. A little further in this chapter, we will return to Mr. Bersani's points on why AIDS targets first of all gay people psychologically and socially, even though it is obvious that biologically it is not a "gay disease" as it used to and still often is referred to, whether implicitly or explicitly.

The main character who we know so much about at this point in the story still remains a nameless stranger to us, and at the same time he is alone representing thousands of those who have got the same diagnosis as he did. The friendly behavior of his acquaintances in its turn becomes the model of common attitude of support in the society as long as the fear does not reach the point of being overwhelming. He is definitely perceived as different by the majority and there is a degree of either hypocrisy or confusion in the way some of his friends talk about him, the unintentional slips of the tongue reveal it here and there: "I don't think about whether I'm at risk or not, said Hilda, I know that I was afraid to know someone with the disease, afraid of what I'd see, what I'd feel, and after the first day I came to the hospital I felt so relieved. I'll never feel that 
way, that fear, again; he doesn't seem different from me. He's not, Quentin said" [592]. This short but powerful response of Quentin to Hilda's “doesn't seem different from me" ends one of the few paragraphs of the story making an important point again that the main character becomes rather a symbol of their hope that they are fine as long as they are different from what he is. They rest assured that while they are visitors and on the other side of this "patient-visitor" role-playing they are all safe and sound so far. “Though some of us are dropping out, as Xavier pointed out, aren't we getting at least as much out of this as he is" [593].

In the meanwhile they receive the news about others being infected and it gets harder to rely on this vague symbol of the difference between them that used to promise safety to some extent. The rituals of showing love or at least affection and support are slowly becoming a burden which is soon replaced with frustration and tiredness of telling lies and the necessity to pretend that everything is going to change for the better. "But did you ever think, Greg said, that if some people don't die, I mean if they can keep them alive (they, they, muttered Kate), they continue to be carriers, and that means, if you have a conscience, that you can never make love fully, as you'd been wont - wantonly, Ira said - to do" [594]. More people are reported to be ill again and it causes a new transition in the perception of the main character. Instead of being a victim he is also viewed as one of those who created the problem. He is now one of those who are responsible for the disease because they were not careful enough and allowed all of this to happen to them, to be afflicted and then transmitted it to others. He is a "carrier" of the disease who did not value life over sex and failed to be cautious about the risks on time. "He must feel awfully foolish now, said Betsy, like someone who went on smoking, saying I can't give 
up cigarettes, but when the bad X-ray is taken even the most besotted nicotine addict can stop on a dime" [595].

This particular aspect of such attitude of blaming the tragic results on the victim obtained even by other gay characters of the story can be explained with a reference to Leo Bersani's discussion of the problem in his chapter "Shame on You" from the book Intimacies, co-authored with Adam Phillips. In his research, Bersani draws attention to the fact that "it is difficult for HIV-infected gays not to be also infected by the shameinducing judgment that AIDS is a punishment for their sexual sins" [Bersani, 32]. Mr. Bersani also points out that if gay-shame is fundamental in a society that from early childhood of gay people cultivates the perception of homosexuality as unnatural and even criminal then in case of facing a life-threatening disease such perception hardly fails to bring to mind that promoted shame of same-sex practices. And as it happens in Susan Sontag's story, some characters are subject to gay shame even though their sexuality does not differ from the main character's, in accordance with Bersani's point of view, because they see AIDS as a punishment for the main character's life-style and sexuality.

The confidence of characters is shattered. They learn that they can be infected and not know about it yet. Bad news eventually separates friends into two groups, those who are going to stay around no matter what and those who have become exhausted, angry, and desperate. The latter try to find any excuses not to be there for the main character anymore. The struggle is no longer confined to the hospital room where their friend is dying. Hilda, one of those who have given up, had learned that her seventy-five-year-old aunt was dying of the disease which she had contracted from a transfusion five years ago. Max is now hospitalized himself. The fears and hopes cannot be kept in this little cage of 
the hospital room any more. The deadly ill patient is no longer the one whose condition is unique, and he cannot be used as an example of who you have to be in order to be susceptible, in order to die. Things have changed and to those few faithful friends who are still around he is not a proof that they are different and can be in peace. Only a few of them realize that he is actually like them, that even though some denied it their behavior was no different from his before he got ill. They figure out that they are there not as much to support him as to learn from what they see. 'It's undeniable, isn't it, said Kate on the phone to Stephen, the fascination of the dying. It makes me ashamed. We're learning how to die, said Hilda, I'm not ready to learn, said Aileen" [598].

And those who stayed around have time to be rewarded with the knowledge that they are no different from him. They are learning who they really are according to how they act around the main character and what they think about him. The characters of the story are waiting to find out that they can learn how to be prepared for either outcome, even if it means to be in peace with no recovery. Or possibly they will happen to learn that all of it is not as terrifying as they perceive it, because "He is still alive... He's still alive, Stephen said" [598] is the last sentence in the text. Such ending reveals both their astonishment and hope for the better.

While chapters 2 and 3 are focused on the characters that are marginalized because they are different by people who are "normal" from their own point of view, the stories by Susan Sontag and Reginald McKnight provide, in chapter 4, examples of selfinflicted hatred and discrimination. The outcasts in both stories are alienated by other outcasts who fall into the same category as they do (same race, same sexuality). Their haters are stimulated by their own survival instinct when their well-being is in danger. 
The oppressors in these two stories are in denial of their own abnormal identity. The term "abnormal" in used here only in the context of their social environment from which they happen to be alienated. The reasons for conflict in both cases are not in fighting for the domination of your own team, but rather the fear of belonging to your own team and being in danger because of that, by association. Such fears are imposed by the dominant model of role in each particular situation, where characters are forced to turn against their own people by the norm shaped by predominant stereotypes and standards in the majority group. 


\section{Conclusion}

Even though Leo Bersani states in his work Is the Rectum a Grave, "There is no longer a rationale for the oppression of blacks in America, while AIDS has made the oppression of gay men seem like a moral imperative" [Bersani, 204], it is hard to support this statement reading J. Patrick Johnson's research on the discrimination of people of color. Not only it still exists, it transforms switching from memories of segregation to association with higher level of crime in ghettos and lower level of education. Native Americans, as Malea Powell admits in Listening to Ghosts: An Alternative (Non)Argument, till this day experience the oppressive patterns of behavior and loss of identity after centuries of living on the same land. Especially, the task of defining what social groups are most vulnerable before the discrimination gets harder as soon as multiple identities overlap in the same individual who can belong to several oppressed groups simultaneously, being black and disabled or Jewish and gay at the same time, for example.

The analyzed types of marginalization allow drawing some parallels and conclusions. First of all, the diversity of so-called "abnormal" or different characters only a few of which have been used as examples in this particular work eliminates the space for any pure norm that would be applicable in every society or context. Hatred and discrimination are not inspired as much by the different characters themselves in these particular stories, but their difference from others is rather a creation of fears and insecurities shaped by traditions and lack of knowledge, by the basic instinct of procreation based on the fear of death. End the discriminated ones are not necessarily 
oppressed by those who have more power in a given context. The diversity in gay community is so vast that it sometimes makes the discrimination within the community itself being possible like in Susan Sontag's The Way We Live Now. Also, people of color may discriminate the fellow members of their own ethnic group on the grounds of racism, as in The Kind of Light That Shines on Texas by Reginald McKnight. Though such examples are variations of very common patterns of marginalized people being oppressed by the majority, or because of prejudices based on what is stereotypically more common for the majority, hence more acceptable, in a particular social group.

Our society is far from being free of categories of compulsory norm. As E. Patrick Johnson puts it: "Rather than signify a site of productive identity contestation, the melting pot metaphor paradoxically highlights the impossibility of monolithic "American" and calls attention to the ways in which the erasure, or "melting," of difference signals the hegemony of white supremacist patriarchy" [Patrick Johnson, 251]. So, the differences existed and they will exist, and there is not much hope for complete eradication of customary differentiation between "us" and "them". The more relevant question is how we can approach our differences with the understanding that would not create fears and insecurities. At least, the ideas of the superiority of some groups over others can be slowly and patiently overcome. One of the ways to do so is to use the help of literature. "Becoming aware of this process encourages the writer to express silenced or marginal positions by highlighting for the reader how such positions have been silenced by discursive norms," as Luann Barnes suggests [57].

It is clear that norm varies from one social group to another. And Judith Butler asks a rhetorical question that seems very appropriate in the context of this research: 
"How can something operate as an origin if there are no secondary consequences which retrospectively confirm the originality of that origin?" [Butler, 313]. The answer to that question, that does not require an answer, can be given with a quote from Gilbert Herdt: "We should resist the reduction of the full human person to merely a social, gendered, or sexual role". [Herdt, 106]. It is crucial to recognize the differences, acknowledge and accept them supporting diversity and at the same time to learn that different does not mean inferior or dangerous. It would be better to say that diversity means that each of us is not different from others but unique. Such results may not soon be achieved, but the progress on the way to it is in diversification of voices in creative writing, academia and media. Taking an approach of representation of various perspectives we will become closer to understanding the diversity of different and familiar in the context of multicultural society. This way we can help ourselves to recognize that prejudice and stereotypes are playing a great role in formation of our fears and insecurities which need to be dismantled in order to make peaceful coexistence possible. 


\section{References}

1. Barnard, Ian. Queer Race: Cultural Interventions in the Racial Politics of Queer Theory. Vol. 3 of "Gender, Sexuality, and Culture" Series. General Ed. William J. Spurlin. New York: 2004

2. Barnes, Luann and Lecourt, Donna. "Writing Multiplicity: Hypertext and Feminist Textual Politics.” Computers and Composition 16 (1999): 55 - 71.

3. Bergner, Gwen. Taboo subjects: Race, Sex, and Psychoanalysis. Minneapolis: University of Minnesota Press, 2005, 209.

4. Bersani, Leo and Phillips, Adam. Intimacies. Chicago: The University of Chicago Press, 2008.

5. Bersani, Leo. "Is the Rectum a Grave?” October 43 (1987): 197 - 222.

6. Bloom, Amy. "Silver Water." The Scribner Anthology of Contemporary Short Fiction: 50 North American Short Stories Since 1970. Ed. Lex Williford and Michael Martone. New York: Simon \& Schuster, 2007. 72 - 79.

7. Boyle, T. C. "Caviar." The Scribner Anthology of Contemporary Short Fiction: 50 North American Short Stories Since 1970. Ed. Lex Williford and Michael Martone. New York: Simon \& Schuster, 2007. 80 - 92.

8. Brown, Linda Joyce. The Literature of Immigration and National Formation: Becoming White, Becoming Other, Becoming American. New York: Routledge, 2004. 138

9. Butler, Judith. "Extracts from Gender as Performance: An Interview with Judith Butler." URL: http://www.theory.org.uk/but-int1.htm 
10. Butler, Judith. "Imitation and Gender Insubordination." The Lesbian and Gay Studies Reader. Ed. Henry Abelove, Michele Aina Barale, David Halperin. New York: Routledge, 1993. $307-320$.

11. Doerr, Anthony. "The Caretaker." The Scribner Anthology of Contemporary Short Fiction: 50 North American Short Stories Since 1970. Ed. Lex Williford and Michael Martone. New York: Simon \& Schuster, 2007. $152-180$.

12. Gourdine, Angelette K. M. The Difference place Makes: Gender, Sexuality, and Diaspora Identity. Columbus: The Ohio State University Press, 2002. 135

13. Herdt, Gilbert. "Third Genders, Third Sexes." A Queer World. Ed. Martin Duberman. New York: New York University Press, 1997. 100 - 107.

14. Hrbek, Greg. "Sagittarius." The Best American Short Stories 2009. Ed. Alice Sebold, Heidi Pitlor. New York, Boston: Houghton Mifflin Harcourt, 2009. 106 117.

15. Justad, Mark. “A Transvaluation of Phallic Masculinity.” Journal of Men's Studies. 4.4 (1996) 355 - 374.

16. Kosofsky Sedgwick, Eve. Tendencies. Duhram: Duke University Press, 1993. 17. Lloyd-Smith, Allan Gardner. Uncanny American Fiction: Medusa's Face. New York: St Martin's Press, 1989. 186.

18. Marmon Silko, Leslie. “Tony's Story.” The Scribner Anthology of Contemporary Short Fiction: 50 North American Short Stories Since 1970. Ed. Lex Williford and Michael Martone. New York: Simon \& Schuster, 2007. 579 - 584.

19. McKnight, Reginald. "The Kind of Light That Shines on Texas." The Scribner Anthology of Contemporary Short Fiction: 50 North American Short Stories Since 
1970. Ed. Lex Williford and Michael Martone. New York: Simon \& Schuster, 2007. $386-396$.

20. Muller, Gilbert H. New Strangers in Paradise: The Immigrant Experience and Contemporary American Fiction. Lexington: The University Press of Kentucky, 1999. 270.

21. Patrick Johnson, E. "Mother Knows Best: Black Gay Vernacular and Transgressive Domestic Space”. Speaking in Queer Tongues. Ed. William Leap and Tom Boellstorff. Urbana: University of Illinois Press, 2004. 251 - 278.

22. Powell, Malea. "Listening to Ghosts; An Alternative (Non)Argument." AlternateDiscourses and the Academy. Ed. Christopher Schroeder, Helen Fox, and Patricia Bizzel. Portsmouth, NH: Boynton/Cook, 2002. 11 - 22.

23. Rawson, K. J. "Queering Feminist Rhetorical Canonization.” Rhetorica in Motion: Feminist Rhetorical Methods and Methodologies. Ed. Eileen Schell and K. J. Rawson. Pittsbourgh: University of Pittsburgh Press, 2010. 39 - 52.

24. Rich, Adrianne. "Compulsory Heterosexuality and Lesbian Existence". The Gay and Lesbian Studies Reader. 227 - 254.

25. Sontag, Susan. "The Way We Live Now". The Scribner Anthology of Contemporary Short Fiction: 50 North American Short Stories Since 1970. Ed. Lex Williford and Michael Martone. New York: Simon \& Schuster, 2007. 585 598.

26. Tanner, Laura. Lost Bodies: Inhabiting the Borders of Life and Death. Ithaca and London: Cornell University Press, 2006, 264. 
27. Warner, Michael. The Trouble With Normal: Sex, Politics, and the Ethics of Queer. Cambridge, Massachusetts: Harvard University Press, 2000, 227.

28. Witzling, David. Everybody's America: Thomas Pynchon, Race, and the Cultures of Postmodernism. New York: Routledge, 2008, 223

29. Wolff, Tobias. The Salon Interview. 1 - 2 URL:http://www.salon.com/dec96/interview2961216.html 